\title{
Usabilidade do sistema de gestão de finanças públicas do Estado do Rio Grande do Sul
}

\author{
Mateus Schuch da Silva1,3, Daniela D. S. Bagatini ${ }^{1,4,5}$ and Rejane Frozza ${ }^{1,2}$ \\ ${ }^{1}$ Departamento de Computação - Universidade de Santa Cruz do Sul (UNISC) and ${ }^{2}$ Programa de Pós-Graduação \\ em Sistemas e Processos Industriais - Universidade de Santa Cruz do Sul (UNISC) and ${ }^{3}$ Companhia de \\ Processamento de Dados do Estado do RS - PROCERGS and 4 Programa de Pós-Graduação em Informática na \\ Educação (PPGIE) - Universidade Federal do Rio Grande do Sul (UFRGS) and ${ }^{5}$ Centro Universitário FADERGS \\ *mat.dasilva@gmail.com; bagatini@unisc.br; frozza@unisc.br
}

Recebido: 03/11/2018. Revisado: 17/01/2019. Aceito: 13/03/2019.

\begin{abstract}
Resumo
Em muitos casos o que compromete a vida de um software não é um problema de funcionalidade, mas as dificuldades de usabilidade. Todo projeto de software que tenha o compromisso de apoiar seus usuários, deveria preocupar-se com a experiência positiva dos mesmos para lidar de forma satisfatória e produtiva com os sistemas computacionais. Tendo como orientação a área de Interação Homem-Computador com ênfase em Usabilidade de Sistemas, o presente trabalho aborda métodos e processos para a avaliação de usabilidade e, com base neles, tem como objetivo apresentar requisitos identificados como sugestões de melhoria da usabilidade para melhorar a interação do Sistema de Gestão de Finanças Públicas do Estado do Rio Grande do Sul (FPE) com seus usuários. Tais requisitos foram apontados pelos próprios usuários que participaram de sessões de avaliação heurística e de testes de usabilidade. Os resultados obtidos indicaram contribuições e evidenciaram a importância da avaliação de usabilidade em projetos de sistemas.
\end{abstract}

Palavras-Chave: Avaliação de Interfaces; Interação Homem-Computador; Sistema FPE; Sistema de Gestão de Finanças Públicas do Estado do Rio Grande do Sul; Usabilidade

\begin{abstract}
In many cases that compromises the life of a software is not a functionality problem, but the difficulties of usability. Every software project that has committed to supporting its members should worry about the positive experience of them to deal satisfactorily and productively with computer systems. With the orientation area of Human-Computer Interaction with emphasis on usability of systems, this paper discusses methods and processes for the evaluation of usability and, based on them, it aims to present requirements identified as usability improvement suggestions to improve the interaction of the Sistema de Gestão de Finanças Públicas do Estado do Rio Grande do Sul (FPE) to its users. Such requirements were pointed out by the users who participated in heuristic evaluation sessions and usability tests. The results obtained indicated contributions and evidenced the importance of the usability evaluation in systems projects.
\end{abstract}

Key words:

Human-computer interaction; Sistema FPE; Sistema de Gestão de Finanças Públicas do Estado do Rio Grande do Sul; Usability; User Interface Evaluation 


\section{Introdução}

O usuário deve se preocupar somente com o problema que deseja resolver; essa deveria ser a premissa básica para qualquer sistema que tenha seu projeto orientado pelas boas práticas da Engenharia de Software e a área de Interação Homem-Computador. A Interação Homem-Computador, especialmente a subárea de Usabilidade, está interessada na qualidade de uso desses sistemas e no impacto na vida dos seus usuários. Conforme pesquisas realizadas por Nielsen em mais de 60 empresas, um baixo nível de usabilidade diminui a produtividade dos colaboradores (Nielsen; 2012). Para Dias (2003, p. 26), usabilidade é "a capacidade de um produto ser usado por usuários específicos para atingir objetivos específicos com eficácia, eficiência e satisfação em um contexto específico de uso".

Tendo como referência a definição de usabilidade que trata da capacidade da aplicação de ser compreendida, aprendida e operada, coloca-se em discussão neste trabalho as características de interface e de interação do Sistema de Gestão de Finanças Públicas do Estado do Rio Grande do Sul (FPE).

O Sistema de Gestão FPE é um sistema de informação web desenvolvido pela Companhia de Processamento de Dados do Estado do Rio Grande do Sul (PROCERGS), com o objetivo de permitir o perfeito gerenciamento e controle da execução orçamentária, extra orçamentária e financeira da despesa e da receita do Estado, visando à diminuição de custos, incremento na eficácia e eficiência, além da transparência na gestão dos recursos públicos pelos órgãos públicos do Estado do Rio Grande do Sul.

Contudo, desde o ano 2000, quando o Sistema de Gestão FPE foi concebido, a web sofreu diversas modificações e atualizações em conceitos e guidelines de usabilidade, o que não foi refletido nos guias existentes na PROCERGS e, consequentemente, no processo de desenvolvimento das novas funcionalidades e validações de usabilidade do sistema. Como efeito os usuários começaram a encontrar dificuldades na utilização do sistema, ocasionando queda na eficácia, eficiểncia e satisfação.

Com base neste contexto, apresenta-se o estudo e a avaliação de usabilidade realizada do Sistema de Gestão FPE. Como método de pesquisa, os procedimentos adotados foram: (1) revisões das guidelines da PROCERGS; (2) avaliações heurísticas com auxílio de especialistas do Sistema de Gestão FPE; (3) validação dos requisitos levantados na avaliação em testes com usuários do sistema. Como resultado de pesquisa, fez-se a proposta de aprimoramento da interação do sistema com seus usuários, através de requisitos identificados como sugestões de melhoria da usabilidade. Desta forma, a pesquisa busca contribuir e apresentar possibilidades para suprir as necessidades dos usuários e aprimorar a satisfação do uso do sistema de Gestão FPE.

\section{Sistema de Gestão de Finanças Públicas do Estado do Rio Grande do Sul}

O Sistema Orçamentário e Financeiro (SOF) do Estado do Rio Grande do Sul, sob a responsabilidade do
Departamento da Despesa Pública Estadual (DDPE), registra a receita prevista e as autorizações legais de despesa constantes da Lei Orçamentária Anual e dos créditos adicionais, demonstrando a despesa fixada e a realizada no exercício. Este sistema, também compara a receita prevista com a arrecadada (Orçamentário), registra a arrecadação da receita e o pagamento da despesa orçamentária e extra orçamentária (Financeiro). Contudo, existe um conjunto de processos da despesa e da receita que são afetos à Contadoria e Auditoria-Geral do Estado (CAGE), contemplados pelo sistema Administração Financeira do Estado (AFE). O sistema AFE realiza a gerência orçamentária, financeira e contábil da Administração Direta do Estado, poderes Executivo, Legislativo e Judiciário, assim como da Administração Indireta, Fundações e Autarquias.

O Estado constatou a necessidade de ampliar, complementar e revisar os processos Orçamentários e Financeiros, assim como contribuir com o compromisso do Governo com a transparência da gestão, o fortalecimento do controle social e a prevenção à corrupção. A decisão tomada foi a de tornar o SOF e o sistema AFE um projeto único, com o desenvolvimento de um sistema integrado que contemple todas as fases da despesa e da receita, permitindo um completo controle financeiro, orçamentário e extra orçamentário, unificando procedimentos e bases de dados.

Assim nasceu o projeto do Sistema de Gestão de Finanças Públicas do Estado do Rio Grande do Sul (FPE), com o objetivo primário de prover um sistema de informação que permita o perfeito gerenciamento e controle da execução orçamentária, extra orçamentária e financeira da despesa e da receita do Estado, visando à diminuição de custos, incremento na eficácia e eficiência, além da transparência na gestão dos recursos públicos. Como objetivos secundários, este projeto contempla:

i. Implantar um novo modelo de gestão da execução de despesas públicas.

ii. Melhorar o gerenciamento, acompanhamento e controle de toda a execução orçamentáriofinanceiro.

iii. Prover a Secretaria da Fazenda do Rio Grande do Sul de um sistema de informações tecnologicamente atualizado, permitindo um melhor planejamento orçamentário e financeiro, viabilizando análises e previsões mais apuradas, através de projeção de cenários econômicofinanceiros com simulações parametrizadas.

iv. Realizar o desenvolvimento do projeto integrado entre a DDPE e CAGE que contemple todas as fases e processos da despesa e da receita, culminando na implantação de um sistema que unifique procedimentos e bases de dados.

\subsection{Clientes e usuários do Sistema FPE}

Atualmente os principais clientes do Sistema FPE são:

- CAGE

- Divisão de Custos e Controles Especiais (DCC)

- Divisão de Tecnologia e Projetos (DTP) 


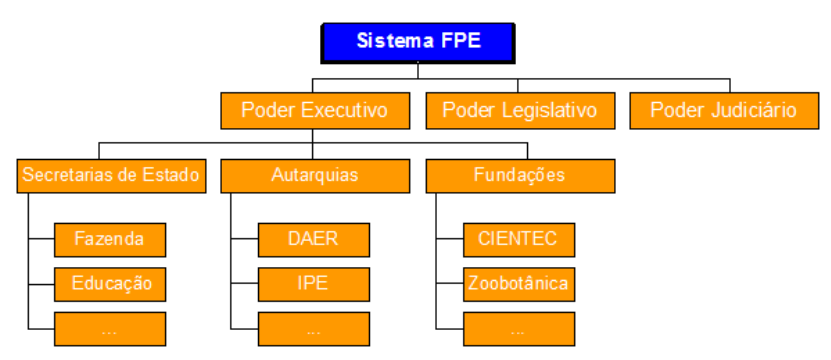

Figura 1: Organograma dos usuários do Sistema FPE.

\section{- Tesouro do Estado}

- Divisão de Tecnologia e Desenvolvimento Institucional (DTDI)

- Divisão de Planejamento Financeiro e do SIAC (DEPLANSIAC)

- Divisão de Programação e Execução Orçamentária (DPO)

- Divisão de Programação e Execução Financeira (DPROF)

- Divisão de Estudos Econômicos e Fiscais e Qualidade do Gasto (DEEFQG)

Os usuários do Sistema FPE são todos órgãos do Poder Judiciário, Legislativo e Executivo, incluindo as Secretarias de Estado, Autarquias e Fundações (Figura 1). O símbolo dos três pontos (...) indicado na figura simboliza as demais Secretarias de Estado, Autarquias e Fundações que utilizam o sistema, além daquelas citadas. A relação entre os clientes e usuários do sistema é de suporte, onde os clientes auxiliam na forma de utilização das funcionalidades.

\section{Usabilidade de Sistemas}

Dispositivos de comunicação e computação estão intrínsecos na vida dos seres humanos, sejam eles para realizar o pagamento do supermercado, alugar um filme na televisão, a seleção do programa na máquina de lavar roupa através do painel sensível ao toque ou na realização das atividades de trabalho. Esta disponibilidade de acesso e uso da Tecnologia da Informação e da Comunicação (TIC) coloca em foco uma discussão especial no desenvolvimento destes sistemas, que é a preocupação com a usabilidade.

Para um usuário uma boa interação significa conseguir realizar uma tarefa com sucesso, sem dificuldades, riscos e frustrações. A não aceitação de um sistema por parte dos usuários significa o insucesso de um sistema. Por esta razão pensar na usabilidade é pensar a partir dos requisitos dos seus potenciais usuários, ou seja, é pensar na Interação Humano-Computador.

\subsection{Usabilidade}

A usabilidade sempre foi a principal busca da Interação Humano-Computador, sendo um atributo de qualidade relacionado à facilidade do uso do sistema. A usabilidade "refere-se à rapidez com que os usuários podem aprender a usar alguma coisa, a eficiência deles ao usá-la, o quanto lembram daquilo, seu grau de propensão a erros e o quanto gostam de utilizá-la"(Nielsen and Loranger; 2007, p. xvi).

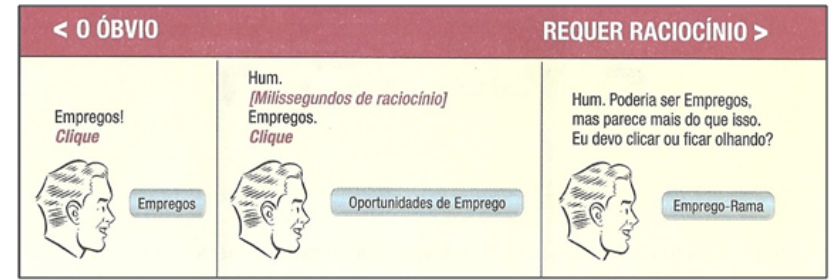

Figura 2: Coisas que nos fazem pensar Fonte: (Krug; 2014, p. 12)

Nielsen (1993) reforça que a usabilidade não é uma propriedade única, já que ela possui múltiplos componentes e tradicionalmente é associada a cinco atributos: facilidade de aprendizagem; eficiência; facilidade de relembrar; erros; e satisfação subjetiva.

Krug (2014) vai além dos atributos mencionados por Nielsen (1993), criando os seus próprios atributos para definir a usabilidade. São eles:

- Não me faça pensar: Frase título de seu livro, Krug defende esta frase como sendo sua primeira lei para definição da Usabilidade. Quando uma pessoa examina uma página web, ela deve ser capaz de "entendê-la"sem ter de esforçar-se para isso. A Figura 2 ilustra o nível de esforço que uma pessoa deve ter ao examinar um botão de uma página web. - Não importa quantas vezes eu tenha de clicar, desde que cada clique seja uma escolha impensada e não ambígua.

- Livre-se de metade das palavras de cada página. Depois, livre-se de metade das que restaram: Terceira lei de Krug encoraja os designers a retirarem todo o texto desnecessário das páginas ou telas dos sistemas, pois na maioria das vezes, elas estão lá apenas para ocupar espaço e dar uma falsa ideia de que o usuário precisa destas informações.

\subsection{Avaliação de Interfaces}

O design de interfaces é essencialmente o design da navegação e da apresentação da informação, uma questão de equilibrar a estrutura e as conexões de menu, conteúdos e outras conexões para documentos e gráficos com o objetivo de criar uma hierarquia de menus e páginas de forma natural, bem estruturado e de uso fácil.

Durante o processo de design das interfaces de um sistema, tem-se o processo de avaliação das interfaces. Conforme Rocha and Baranauskas (2003, p. 161), "A avaliação de interfaces não deve ser vista como uma fase única dentro do processo de design e muito menos como uma atividade a ser feita somente no final do processo e se 'der tempo'".

A avaliação de interfaces tem por objetivo conhecer melhor o que os usuários querem e os problemas que eles experimentam. Estas avaliações são necessárias para responder questões que surgem durante o processo de design e desenvolvimento de um produto. Resumindo, as avaliações possuem três principais objetivos: "avaliar a funcionalidade do sistema, avaliar o efeito da interface junto ao usuário e identificar problemas específicos do sistema."(Rocha and Baranauskas; 2003, p. 163) 
Com base nesses objetivos, é possível classificar os métodos de avaliação em duas dimensões: (1) se os usuários estão envolvidos ou não e (2) se a interface está ou não implementada (protótipo executável). Nessas dimensões apresentam-se dois grupos de métodos: Inspeção de Usabilidade e Testes de Usabilidade.

A Inspeção de Usabilidade provê a aplicação de métodos realizados por avaliadores que examinam aspectos relacionados à usabilidade de uma interface. Entende-se avaliadores como sendo especialistas em usabilidade, especialistas em determinado padrão de interface.

Teste de usabilidade é um método eficaz para avaliar interfaces a partir da interação do usuário, porém os custos da aplicação podem se tornar caros e difíceis de realizar em todas as fases do desenvolvimento da interface. Conforme Rocha and Baranauskas (2003, p. 165) "estudos demonstram que muitos problemas encontrados por métodos de inspeção não são detectados com testes de usuários e vice-versa. [...] os melhores resultados são obtidos combinando testes com usuários e inspeções".

A maioria dos métodos de inspeção terão um efeito significativo na interface final somente se forem usados durante o ciclo de vida do projeto. Contudo, muitos designers consideram os métodos intimidadores, muito caros, difíceis e que necessitam muito tempo para serem aplicados. Nielsen propõe a denominada discount usability engineering (engenharia econômica de usabilidade), com métodos baratos, rápidos e fáceis de serem usados (Nielsen; 1993). Avaliação heurística é o principal método dessa proposta.

Durante o processo de design das interfaces do sistema, um pequeno grupo de avaliadores examina a interface e julga suas características em face de reconhecidos princípios de usabilidade, denominados heurísticas. Em um primeiro momento a avaliação é realizada individualmente. Durante a sessão de avaliação cada avaliador percorre a interface diversas vezes, as inspeciona e, encontrando algum tipo de problema, relatam associando-os com as heurísticas que foram violadas (Rocha and Baranauskas; 2003). Acredita-se que de três a cinco avaliadores especialistas sejam capazes de identificar de $75 \%$ a $80 \%$ dos problemas de usabilidades de interfaces computacionais (Nielsen and Mark; 1994).

Adicionalmente ao conjunto de heurísticas gerais a ser considerada em cada componente do diálogo, o avaliador pode também considerar heurísticas específicas da categoria do produto analisado, por exemplo, heurísticas derivadas da análise de produtos similares e seus resultados de uso.

O resultado desta análise são listas com problemas de usabilidade encontrados pelos avaliadores. Estas listas são transformadas em uma única lista, elencando as referências às heurísticas que foram violadas. Os avaliadores não podem simplesmente dizer que não gostam de um determinado aspecto, eles precisam justificar com base nas heurísticas e serem o mais específico possível.

Teste de Usabilidade é um método fundamental de usabilidade que consiste "na observação de uma pessoa de cada vez tentando usar algo (seja um site, um protótipo de site ou um conceito de design) para executar tarefas comuns a fim de que se detectem e se consertem as coisas que o confundem ou o frustram."(Krug; 2014, p. 111).

Os testes de usabilidade são importantes, pois do ponto de vista do usuário é possível ter a certeza de que o sistema realmente funciona, mesmo que este teste seja realizado somente com um usuário, o que é melhor do que não testar com nenhum. Entretanto, como todo tipo de teste, é preciso prestar atenção às questões de confiabilidade (saber se poderia obter o mesmo resultado, repetindo o teste) e validade (se o resultado reflete os problemas de usabilidade que se quer testar).

\section{Estudo de Caso: Usabilidade do Sistema FPE}

Para concepção de um sistema de informática, as equipes de desenvolvimento se baseiam em modelos de ciclo de vida, que auxiliam na análise e definição de requisitos, no planejamento das demandas e sua execução, no processo de validação através de testes e, por fim, na implantação do sistema finalizado para seus usuários.

Contudo, durante o processo de desenvolvimento, muitas vezes é realizada uma validação parcial ou não é validada a usabilidade destes sistemas. Um exemplo deste cenário é o Sistema de Gestão FPE, que possui guidelines para desenvolvimento das páginas web, mas suas avaliações heurísticas (Visibilidade do status do sistema; Consistência e padrões; Ajuda para usuário identificar, diagnosticar e corrigir erros; Ajudas (Help) e documentação) são realizadas parcialmente, assim como os testes de usabilidade com os usuários do sistema.

Esta seção aborda detalhes sobre o funcionamento do Sistema de Gestão FPE, descrevendo a avaliação heurística e testes de usabilidade realizados.

\subsection{Metodologia de pesquisa}

Para este estudo foi realizada uma pesquisa qualitativa, visando compreender e interpretar determinados comportamentos, a opinião, as expectativas e os problemas que os usuários do Sistema FPE encontram na sua utilização. A natureza da pesquisa é exploratória, tendo o intuito de obter a compreensão, o discernimento dos problemas de usabilidade do Sistema de Gestão FPE e as dificuldades de interação dos seus usuários.

\subsection{Projeto Sistema de Gestão FPE}

O Sistema de Gestão FPE foi construído para prover ao Estado um sistema de informação que permita o perfeito gerenciamento e controle da execução orçamentária, extra orçamentária e financeira da despesa e da receita do Estado, visando à diminuição de custos, incremento na eficácia e eficiência, além da transparência na gestão dos recursos públicos.

Em 2007 iniciou-se o projeto FPE, planejado a ter 37 módulos, dentre eles o Planejamento Financeiro, Execução da Despesa, Execução da Receita, Contabilidade, Programação Execução Financeira, Convênios, Contrato Serviço de Terceiros, Contabilidade de Custos e Administração de 


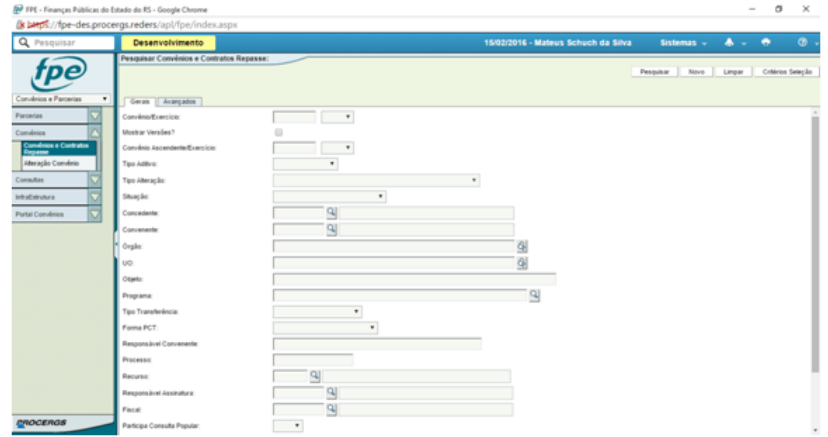

Figura 3: Tela de Pesquisa do módulo Convênios Fonte: (PROCERGS; 2016)

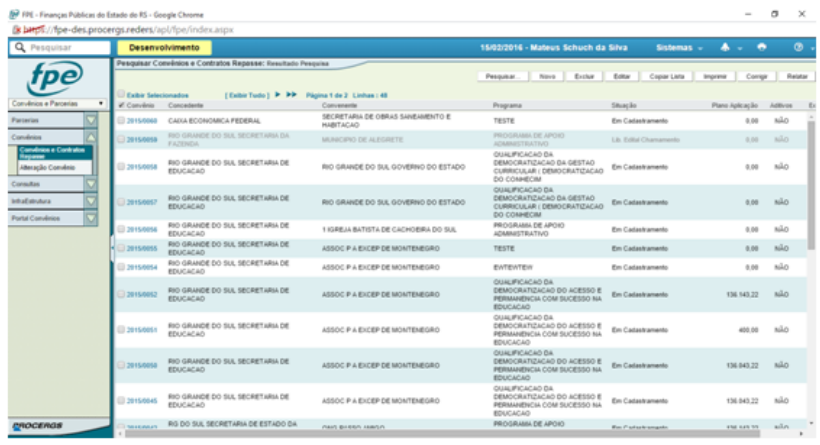

Figura 4: Tela de resultado da Pesquisa Fonte: (PROCERGS; 2016)

\section{Materiais}

Durante o planejamento, foram criados guidelines específicos, padronizando campos de formulários web, mensagem de auxílio ao usuário e comportamento das páginas em todos os módulos, com o intuito de melhorar a sua usabilidade, ou seja, facilitar o uso do sistema, independente do módulo utilizado, tornando rápida a aprendizagem no uso do sistema por parte dos usuários, para que o mesmo possa obter o máximo de eficiência no seu trabalho.

Basicamente os módulos do sistema realizam as quatro operações básicas utilizadas em interfaces para criação, consulta, atualização e exclusão de dados, além da operação de geração de relatórios nos formatos de arquivos PDF e planilhas.

Na operação de consulta os módulos apresentam uma interface com campos para preenchimento do usuário que realiza uma filtragem dos dados existentes no sistema. A Figura 3 demonstra os campos de filtragem do módulo Convênios.

A Figura 4 demonstra a tela de resultado da pesquisa realizada no módulo Convênios. Através desta listagem o usuário poderá atualizar os dados gravados no sistema, selecionando os registros desejados e acessando-os através do botão Editar. Também é possível realizar a inclusão de novos registros (botão Novo) e destruir os existentes, através do botão Excluir.

A Figura 5 demonstra a tela de edição de um registro existente. Através desta tela também é possível realizar a inclusão de novo registro.

A Figura 6 demonstra um relatório com as informações gerais do Convênio, obtidos através do

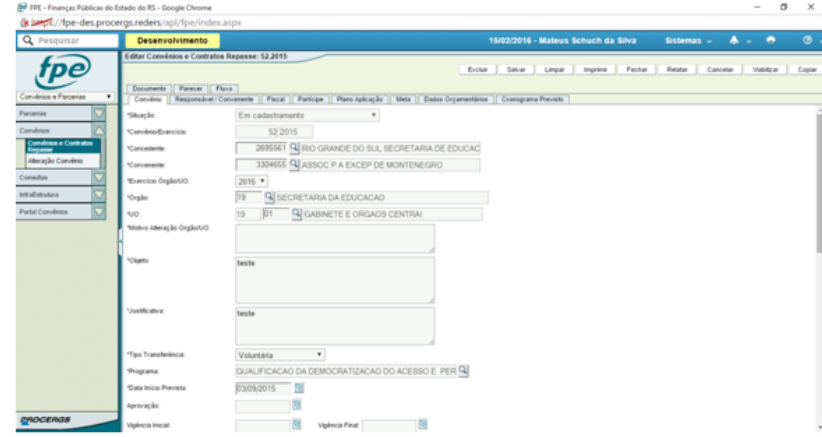

Figura 5: Tela de Edição e Inclusão de registros do módulo Convênios

Fonte: (PROCERGS; 2016)

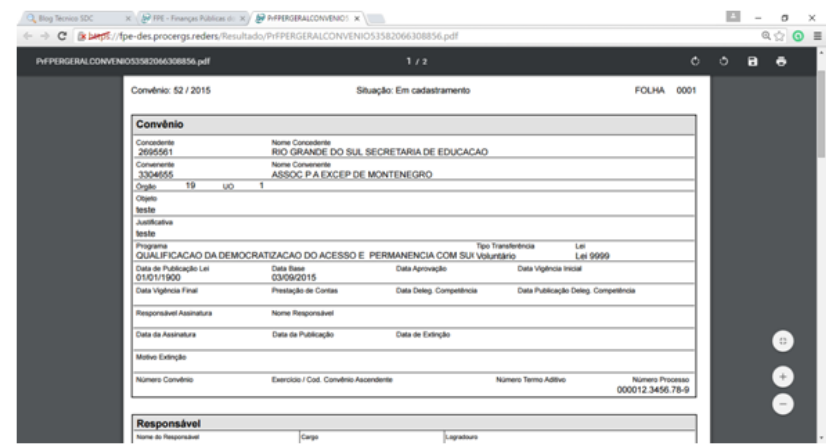

Figura 6: Relatório do registro de Convênio em edição

Fonte: (PROCERGS; 2016)

botão Relatar (ilustrado na Figura 5, no topo da imagem à direita).

Desde 2007 a web passou por diversas modificações e atualizações em conceitos e guidelines de usabilidade. Contudo o Sistema de Gestão FPE não acompanhou estas modificações e atualizações, ocasionando dificuldades para os usuários, por exemplo, a exibição de vários campos de formulário desnecessários, dificultando a visualização das informações importantes daquela página web.

Para aplicação dos conceitos da Usabilidade, selecionou-se o módulo de Convênios. A escolha foi efetuada baseada no conhecimento e na prática cotidiana do autor desta pesquisa. Para realização da avaliação de interfaces foram utilizados dois grupos de métodos: (1) a Inspeção de Usabilidade através da Avaliação Heurística e; (2) o Teste de Usabilidade.

O motivo pela escolha da Avaliação Heurística é pelo fato deste método ser barato, rápido e fácil de ser aplicado. O Teste de Usabilidade foi escolhido por ser um método importante para, através do ponto de vista do usuário, validar se o sistema realmente funciona. Tanto a Avaliação Heurística, quanto o Teste de Usabilidade, foram realizados nos navegadores Internet Explorer 11 e Chrome 48, versões homologadas pela equipe de desenvolvimento do Sistema FPE. 


\subsection{Avaliação Heurística}

A avaliação heurística do módulo foi realizada por três especialistas do Sistema de Gestão FPE responsáveis por outros módulos, todos com mais de seis anos de serviços prestados para PROCERGS no mesmo cargo e com alto nível de conhecimento técnico de desenvolvimento, tanto em programação quanto em análise de sistemas. As sessões de avaliação foram agendadas individualmente com cada especialista, ficando previamente combinada a duração de aproximadamente uma hora. As sessões ocorreram em uma das salas de reunião disponíveis na PROCERGS e mediadas pelo autor deste trabalho, definindo seu papel como moderador das sessões.

Apesar dos módulos do Sistema FPE utilizar as mesmas definições de guidelines, antes de iniciar a avaliação foi feita uma explicação sobre o módulo Convênios, suas operações básicas e as regras de negócio, conforme listado na Tabela 1. Isto foi necessário porque cada módulo possui regras de negócio específicas, cujo conhecimento faz-se necessário para a plena utilização das funcionalidades do módulo. Após, o especialista pode navegar pelas interfaces para uma melhor compreensão do funcionamento do módulo em questão.

Tabela 1: Principais funcionalidades do módulo Convênios

\begin{tabular}{l}
\hline Funcionalidades \\
\hline Adicionar ou editar informações básicas referentes ao \\
Convênio \\
Incluir, alterar ou excluir Fiscais do Convênio \\
Incluir, alterar ou excluir Partícipes \\
Incluir, alterar ou excluir Plano Aplicação \\
Incluir, alterar ou excluir Metas e Etapas \\
Incluir, alterar ou excluir Dados Orçamentários \\
Incluir, alterar ou excluir Cronograma Previsto \\
Incluir ou excluir anexos de Documentos \\
Visualizar histórico de Pareceres \\
Visualizar fluxo do Convênio \\
\hline
\end{tabular}

Dias antes da data marcada para realização das sessões, foi distribuída aos especialistas uma tabela contendo as heurísticas a serem utilizadas e suas respectivas descrições. Assim, eles puderam analisar e compreender melhor as heurísticas e sanar dúvidas antes da sessão de avaliação.

Os problemas reportados ao longo da navegação pelas telas do módulo eram anotados, bem como as heurísticas com as quais esses problemas se relacionavam. Caso os especialistas não tivessem passado por todas as telas do módulo, o moderador intervinha e mostrava os fluxos de atividades que remanesciam inexplorados, para garantir que todas as interfaces seriam visualizadas.

Após o término de cada avaliação, os especialistas eram convidados a responder o grau de severidade para cada problema encontrado. O grau de severidade é uma escala de 0 a 4, sendo o igual a "Eu não concordo que isso seja um problema de usabilidade" e 4 igual a "Catástrofe de usabilidade: é obrigatório corrigir o problema antes que o produto seja liberado".

Após a realização das sessões de avaliação e classificação da severidade de cada problema localizado, os resultados foram agrupados. Evidentemente, alguns problemas foram encontrados por mais de um avaliador. Nestes casos, o problema foi considerado apenas uma vez. Este agrupamento dos problemas está reportado na Tabela 2.

Um dos problemas encontrados foi "Na tela de edição do Convênio, são exibidos muitos campos na aba Convênio"(número sete da Tabela 2), onde a página de edição do Convênio possui diversos campos de formulário que não possuem a necessidade de preenchimento no momento da edição. Como consequência, o usuário pode encontrar dificuldade em realizar determinada funcionalidade desejada, pois as informações apresentadas não são sucintas, exigindo preenchimento desnecessário e tirando o foco do que realmente pode ser importante.

Os resultados dos avaliadores em relação aos graus de severidade associados a cada problema estão dispostos na Tabela 3.

Importante destacar que grande parte dos problemas encontrados pelos especialistas foi classificada como grau três, ou seja, são problemas de usabilidade que precisam ser corrigidos e tratados com prioridade. Isto reforça a tese discutida na seção 4.2, onde a web passou por diversas modificações e atualizações em conceitos e guidelines de usabilidade, mas que o Sistema de Gestão FPE não acompanhou estas modificações e atualizações, ocasionando dificuldades para os usuários.

De posse destes resultados, foram iniciados os testes de usabilidade com usuários do Sistema FPE para identificação de novos problemas e confirmar aqueles encontrados nas avaliações heurísticas pelos especialistas.

\subsection{Teste de Usabilidade}

Nesta etapa do processo de avaliação da usabilidade do Sistema de Gestão FPE, foram seguidas as orientações apresentadas na seção Avaliação de Interfaces. O método contempla os seguintes passos:

- Plano de teste e script: trata da organização e planejamento do teste, assim é elaborado o plano de teste (que contempla: objetivo, local, duração, suporte, recursos, perfil do participante, agendamento do teste, entre outros itens) e o script (roteiro para a condução do teste). O script inclui etapas como: (1) apresentação, (2) ambientação inicial, (3) tarefas e (4) perguntas de encerramento (Krug; 2014).

- Teste de Compreensão: o Sistema de Gestão FPE é apresentado para o participante e é analisado se o mesmo consegue compreender a proposição do sistema, sua organização e funcionamento.

- Teste de Tarefas-chave: o participante realiza tarefas predefinidas. A realização da tarefa evidencia os problemas de usabilidade. Neste momento o participante também contribui com o levantamento de requisitos e sugestões.

- Classificação dos problemas: lista com os problemas encontrados durante a avaliação heurística e os problemas encontrados nos testes de usabilidade. Classificação dos problemas é realizada de acordo com a criticidade, seu nível de importância (se a resolução do problema é 
Tabela 2: Agrupamento dos problemas encontrados pelos avaliadores

\begin{tabular}{|c|c|}
\hline Funcionalidades & Descrição \\
\hline 1 & $\begin{array}{l}\text { Na tela de pesquisa, a organização } \\
\text { dos campos está confusa. São muitos } \\
\text { campos para uma única página. }\end{array}$ \\
\hline 2 & $\begin{array}{l}\text { Na tela de pesquisa, no navegador } \\
\text { Chrome há campos difíceis de } \\
\text { identificar se estão habilitados para } \\
\text { preenchimento ou não. }\end{array}$ \\
\hline 3 & $\begin{array}{l}\text { Alguns campos estão com a descrição } \\
\text { incompatível com a realidade do } \\
\text { usuário. }\end{array}$ \\
\hline 4 & $\begin{array}{l}\text { Devido à quantidade de campos exibidos } \\
\text { na tela, o sistema deveria destacar } \\
\text { melhor qual o campo que está com o } \\
\text { foco do cursor. }\end{array}$ \\
\hline 5 & $\begin{array}{l}\text { Na tela de resultados da pesquisa, } \\
\text { quando clico no link de edição do } \\
\text { Convênio desejado, sistema não } \\
\text { apresenta mensagem alguma de status. }\end{array}$ \\
\hline 6 & $\begin{array}{l}\text { Nos botões de pesquisa auxiliar dos } \\
\text { campos da tela de pesquisa dos } \\
\text { Convênios, é aberta uma janela pop-up. } \\
\text { Além de exibir a página aberta em um } \\
\text { tamanho pequeno, sistema não permite } \\
\text { que usuário redimensione a pop-up, } \\
\text { como também pode causar dificuldade } \\
\text { na localização de qual janela está ativa. }\end{array}$ \\
\hline 7 & $\begin{array}{l}\text { Na tela de edição do Convênio, são } \\
\text { exibidos muitos campos na aba } \\
\text { Convênio, dificultando a navegação e } \\
\text { preenchimento dos dados necessários. }\end{array}$ \\
\hline 8 & $\begin{array}{l}\text { Nas abas seguintes, onde constam os } \\
\text { demais registros do Convênio, é exibida } \\
\text { uma pop-up sempre que desejo incluir } \\
\text { ou editar algum registro existente. } \\
\text { Acaba ficando confuso o preenchimento } \\
\text { destes registros, pois, em determinados } \\
\text { momentos, é necessário várias pop-ups } \\
\text { abertas. }\end{array}$ \\
\hline 9 & 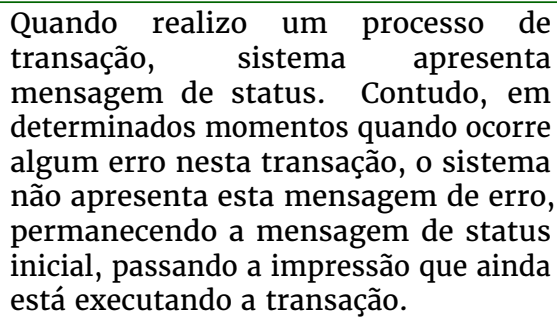 \\
\hline 10 & $\begin{array}{l}\text { Quando vou realizar a alteração da } \\
\text { situação do Convênio, o sistema poderia } \\
\text { esconder alguns campos e botões que } \\
\text { não são importantes para realização do } \\
\text { processo. Isso facilitaria a utilização } \\
\text { por parte do usuário, assim como evitar } \\
\text { possíveis erros. }\end{array}$ \\
\hline 11 & $\begin{array}{l}\text { O botão Relatar pode ser confuso para } \\
\text { usuários novatos. O botão não deixa } \\
\text { explícito qual a sua finalidade, que é } \\
\text { gerar um relatório no formato PDF. }\end{array}$ \\
\hline
\end{tabular}

importante) e a complexidade para a resolução. - Sugestões de melhorias: sugestões de melhorias
Tabela 3: Sumarização das quantidades de problemas encontrados com cada grau de severidade

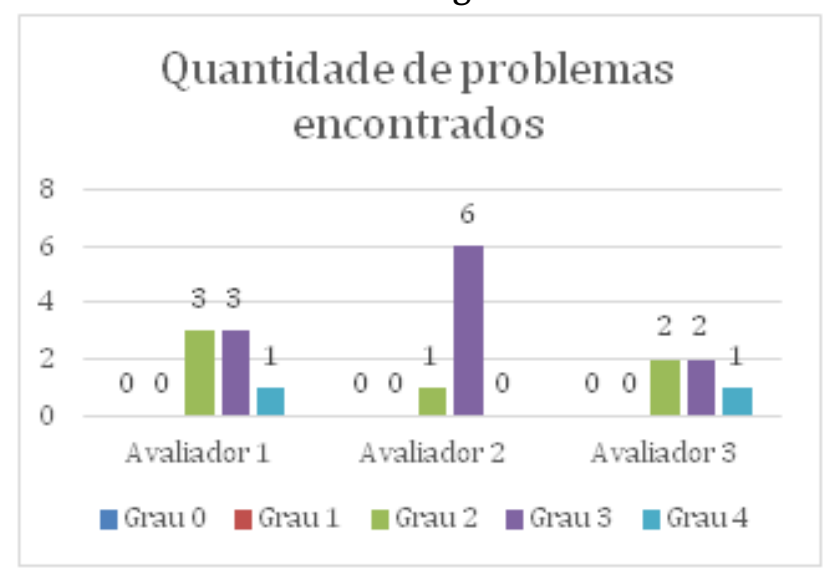

dos problemas classificados críticos ou com o nível de importância médio ou grande.

- Prototipação e validação das novas funcionalidades: criação de protótipo com base nas sugestões de melhorias criadas. Em seguida, realização de novas sessões de testes com os testadores das sessões anteriores para validar se as melhorias sugeridas eliminaram os problemas de usabilidade encontrados na avaliação heurística e nos testes.

Um plano de teste foi escrito baseado em Nielsen (1993). O objetivo do plano de teste foi definir o cenário do teste que integra: o participante, o aplicador do teste, as tarefas realizadas e de que forma os resultados foram analisados.

Definido o plano de teste, iniciou o processo de seleção e convite aos usuários do Sistema de Gestão FPE para realização dos testes. Nielsen (1993) comenta que, na obtenção dos participantes, estes devem possuir o perfil igual ou parecido com o perfil dos usuários finais do sistema em questão. Para tanto, foi solicitado que os responsáveis pela manutenção de cada módulo do Sistema FPE indicasse algum cliente do sistema com disponibilidade e interesse em participar do processo de testes de usabilidade.

Recebida as indicações, foram encaminhados emails de convite com informações sobre este estudo, o funcionamento das sessões de teste de usabilidade e a formalização do convite de participação em uma sessão de teste.

Foram enviados quatro convites, destes três aceitaram participar das sessões. Consideraramse como critério para estabelecer o número ideal as referências de Nielsen e Krug, que afirmam que três usuários são suficientes para testes iniciais de usabilidade.

Dos usuários que responderam confirmando disponibilidade e interesse em participar do processo de testes, foram analisados seus perfis agendadas sessões de testes individuais.

\subsubsection{Script de teste}

Como apoio para aplicação do teste, um roteiro baseado no script descrito por Krug (2014) foi elaborado. $\mathrm{O}$ autor divide o script em quatro etapas: apresentação, ambientação inicial, tarefas e perguntas de encerramento. 


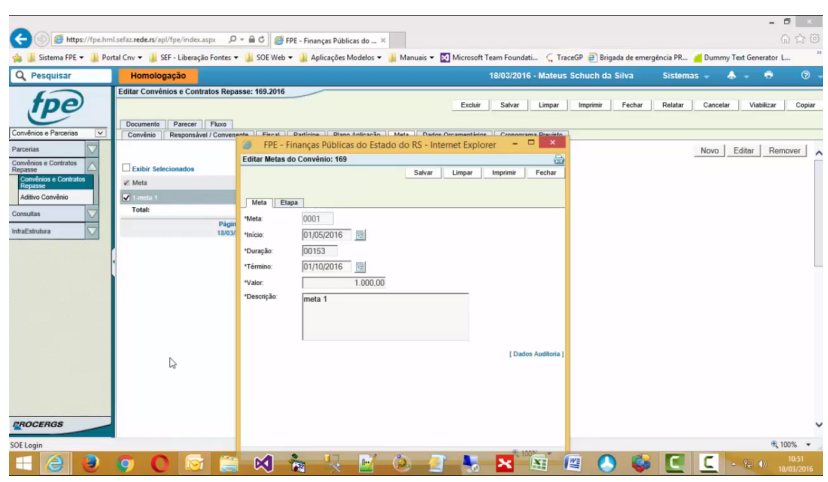

Figura 7: Teste de Usabilidade FPE - Testador 1 (Link)

O roteiro elaborado teve como objetivo, na etapa de apresentação, explicar para o participante que o propósito do teste era verificar a usabilidade da aplicação web e não a sua capacidade. Assim, foi fundamental deixar o participante à vontade para que o mesmo se comportasse da forma mais natural possível.

Na ambientação inicial, o participante foi instigado a descobrir sobre o que tratava a aplicação, relatar as primeiras impressões e comentar sobre a interface atual do Sistema de Gestão FPE.

Após a ambientação, foi solicitado ao participante a realização das tarefas descritas no script. Krug (2014, p. 122) relata que "As tarefas que você testa em dada rodada dependerão parcialmente do que você tem para ser testado. [...], porém, comece listando as tarefas que precisam estar aptas a desempenhar com aquilo que você está testando".

Como o objetivo deste estudo é ajudar no desenvolvimento do sistema, aprendendo quais os aspectos detalhados da interface são bons ou ruins, e como o design pode ser melhorado, foram definidas como tarefas as seguintes atividades: criar, pesquisar, editar e excluir registros, assim como a navegação nas principais páginas do módulo Convênios.

Neste momento, o testador falou em voz alta tudo que estava pensando e justificou todas as suas ações.

Krug (2014) descreve que sempre que for possível, é bom deixar o usuário dar alguma opinião na escolha da tarefa. Seguindo esta recomendação, o roteiro definido no script não foi seguido fielmente, em alguns momentos foi identificada alguma situação onde o participante sugeriu a tarefa ou o moderador percebeu a possibilidade de testar alguma tarefa fora do cronograma de modo a obter o máximo de naturalidade do participante.

Para finalizar o teste foi aplicado um questionário de satisfação e algumas perguntas de encerramento foram feitas ao participante, referente a sugestões de melhorias, o testador também fez comentários sobre o teste e as dificuldades encontradas.

\subsubsection{Execução dos testes}

Para registro, os testes foram gravados e anotações foram realizadas. Estas sessões estão disponíveis nos links descritos nas Figuras 7, 8 e 9.

Krug (2014, p. 117) descreve que "[...] você nunca encontrará todos os problemas no que quer que teste. E não ajudaria caso encontrasse, [...]

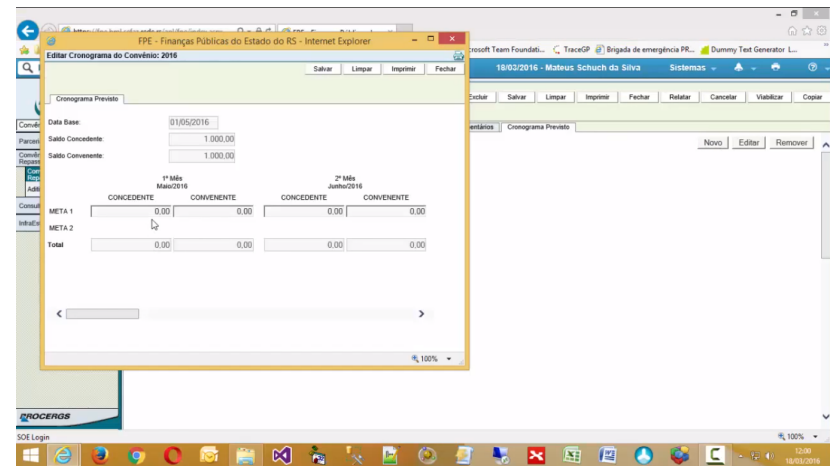

Figura 8: Teste de Usabilidade FPE - Testador 2 (Link)

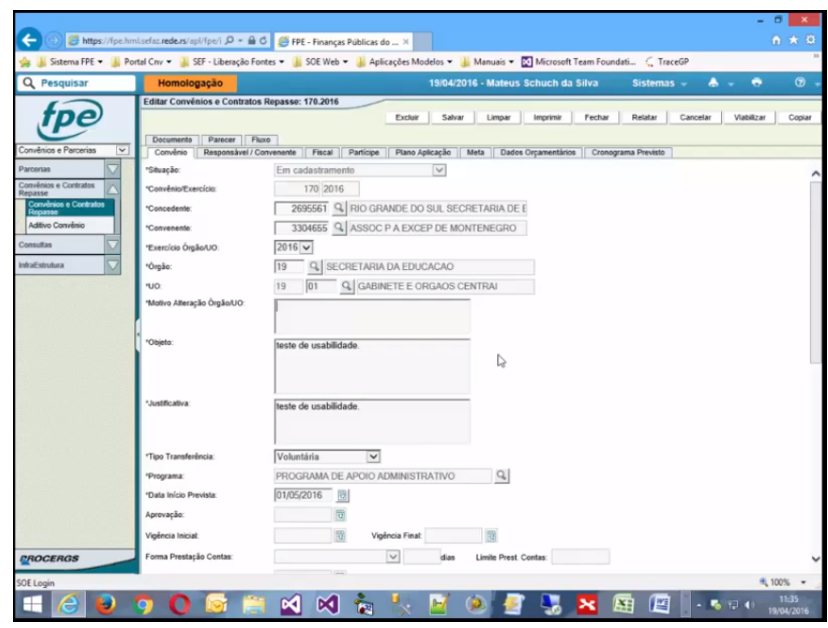

Figura 9: Teste de Usabilidade FPE - Testador 3 (Link)

sempre encontrará problemas maiores do que os recursos disponíveis para solucioná-los, [...] foque em solucionar os mais sérios primeiro".

Seguindo a premissa de focar na solução dos problemas mais sérios, foi realizada a compilação e a geração de uma tabela contendo os erros encontrados durante as sessões de testes, junto com os problemas listados na avaliação heurística. Cada problema foi analisado e classificado conforme sua criticidade (se o problema deve ser solucionado o quanto antes ou não), nível de importância para pleno funcionamento do sistema em uma escala de 1 (menos importante) a 3 (mais importante), e o quão complexo é a resolução deste problema (fácil, médio, difícil). A classificação destes três critérios teve como base o conhecimento e a experiência do autor deste trabalho.

Os problemas classificados como críticos e, também, com nível de importância igual ou maior que dois foram selecionados e sugestões de aprimoramento feitas, através de uma análise crítica da interface do Sistema de Gestão FPE com base em guidelines descrito na seção Avaliação de Interfaces. Para uma visão ampla dos resultados, toda descrição dos problemas selecionados e as sugestões de melhorias foram reunidas na Tabela 4 .

Na primeira coluna dessa tabela estão os problemas representados por um código $(\mathrm{Px}$, sendo $\mathrm{x}$ a numeração). A coluna "Problema" descreve o 


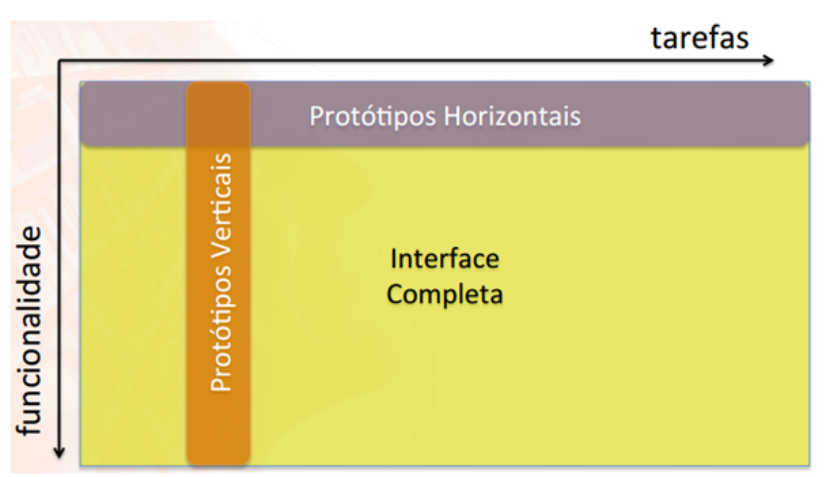

Figura 10: Representação das dimensões Horizontal e Vertical

problema a ser aprimorado. A coluna "Melhoria" descreve a sugestão encontrada através da análise das guidelines para contornar o problema.

\subsubsection{Prototipação e validação das melhorias sugeridas}

Esta seção descreve o protótipo criado com base nas sugestões de melhorias apresentadas e na análise dos testes realizados com objetivo de constar se as melhorias propostas eliminaram os problemas de usabilidade encontrados nos testes de avaliação do Sistema de Gestão FPE.

Para validar as melhorias foi criado um protótipo, que é "uma versão inicial de um sistema de software, usado para demonstrar conceitos, experimentar opções de projeto e descobrir mais sobre o problema e suas possíveis soluções"(Sommerville; 2011, p. 30).

Os protótipos são classificados conforme sua dimensão: Horizontal versus Vertical (Nielsen; 1993). Dimensão Horizontal inclui a interface para todo o sistema, mas sem funcionalidades. Abrange uma maior "largura" com relação ao número de características ou funções contempladas, permitindo testar toda a interface e abranger mais funcionalidades do sistema final.

Já na dimensão Vertical a quantidade (volume) de características é reduzida, tendo o protótipo muita funcionalidade para pouca tarefa. Ela aumenta a "profundidade"com que as características do sistema são abordadas, permitindo testar uma pequena parte do sistema completo. Estas duas dimensões são ilustradas na Figura 10.

Como a ideia do protótipo é apresentar sugestões para os problemas elencados, sem a preocupação de construir funcionalidades mais complexas do sistema, além de abranger o máximo possível o número de características ou funções contempladas, foi utilizado à dimensão horizontal para construção do protótipo.

Para construção do protótipo foi usado o software Justinmind Prototyper Pro Edition Version Trial Ver. 7.1.1 (Justinmind; 2014), uma ferramenta de criação de protótipos para web e aplicativos móveis que oferece capacidades tipicamente encontradas em ferramentas de diagramação, como a função de arrastar e soltar, redimensionar e formatar objetos, criação de interações com o usuário através de links, animações, cálculos e simulação de abas de navegação. Justinmind pode gerar um protótipo em HTML que pode ser exibido em qualquer navegador de internet, assim como a geração de documentação

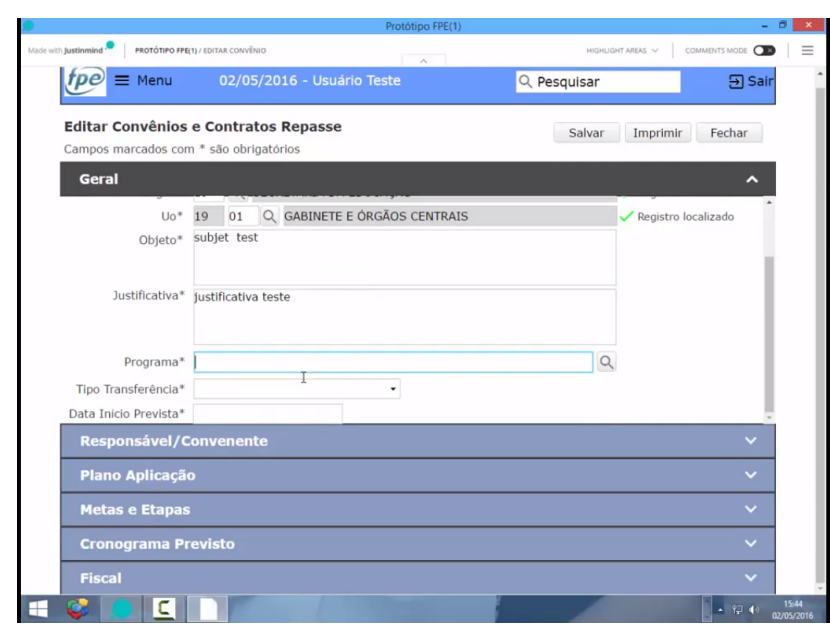

Figura 11: Teste de Usabilidade Protótipo FPE Testador 1 e 2 (Link)

de especificação no formato Microsoft Word.

Para validar as melhorias os testes elaborados seguem as mesmas recomendações de autores que foram utilizadas na elaboração dos testes de usabilidade. O plano de teste e o script são os mesmos apresentados na subseção anterior, apenas adaptando a realização dos testes para o protótipo criado, ao invés do Sistema de Gestão FPE.

Os testes foram aplicados pelo autor deste trabalho (moderador) e os participantes foram os mesmos usuários convidados para realização dos testes de validação. Para realização dos testes foram agendadas uma data e horário combinado com os usuários. Devido à disponibilidade de agenda, os participantes 1 e 2 realizaram a rodada de testes juntos. Para melhor ambientação dos testes, utilizou-se uma sala de reunião no setor onde o moderador trabalha, tendo como suporte computacional um computador com programa TechSmith Camtasia Studio versão 8.6 instalado para captura de vídeo e um celular com um aplicativo de gravação de áudio nativo para registro do áudio da sessão de teste. O navegador utilizado foi o Microsoft Internet Explorar 11. Todos os softwares foram instalados no sistema operacional Microsoft Windows 8.1 versão Professional 64 bits.

$\mathrm{Na}$ fase de ambientação inicial analisou-se a capacidade do usuário em conseguir identificar que o protótipo está representando o Sistema de Gestão FPE. Para isso, o participante realizou tarefas de sua escolha e interagiu livremente com o protótipo.

Após a ambientação inicial, iniciou-se a fase de tarefas que consiste em solicitar ao participante que realizasse algumas atividades. Estas atividades foram elaboradas para conduzir o participante a utilizar os novos recursos implementados.

Por fim, chegou-se à fase de perguntas de encerramento, onde o objetivo foi questionar os participantes sobre as novas funcionalidades, bem como sugestões de melhorias. Para registro, os testes foram gravados e anotações foram realizadas. As gravações destes testes estão disponíveis nos links descritos nas Figuras 11 e 12.

No geral as sugestões de aprimoramentos apresentadas no protótipo foram bem aceitas pelos participantes, havendo poucas sugestões de melhorias. Por exemplo, os testadores 1 e 2 sugeriram 


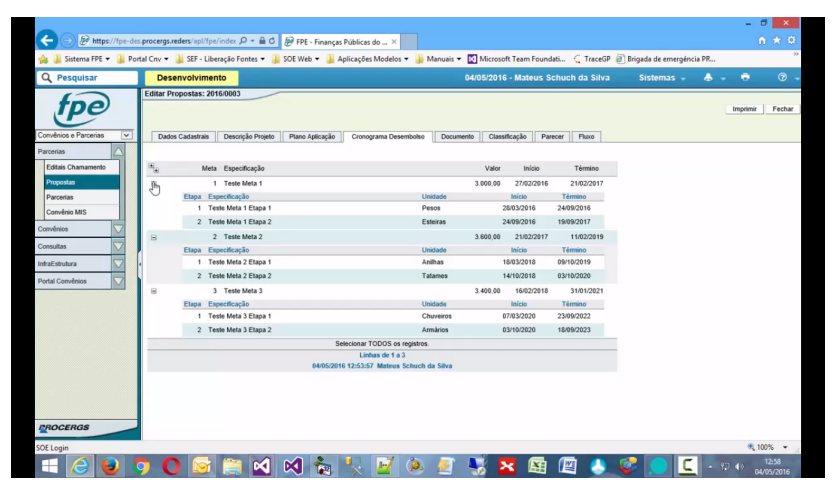

Figura 12: Teste de Usabilidade Protótipo FPE Testador 3 (Link)

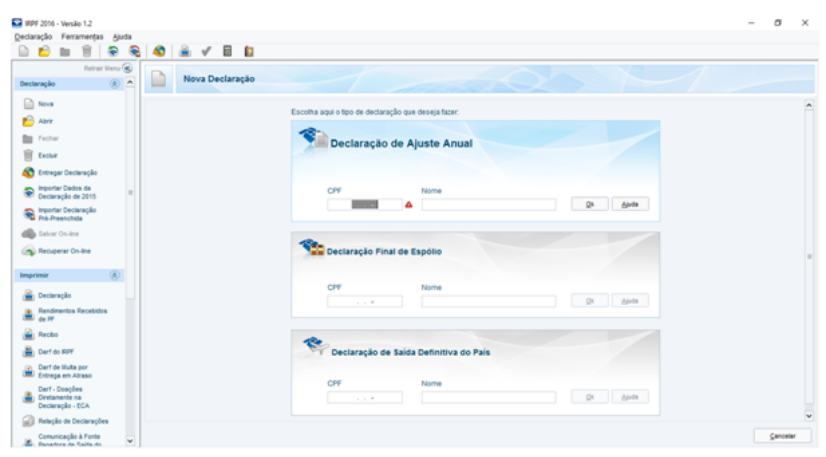

Figura 13: Tela de cadastro da Declaração do Imposto de Renda Pessoa Física

modificar a forma como foi representada as abas no formato accordion (sanfona) para o formato apresentado pelo programa de Declaração do Imposto de Renda Pessoa Física. As abas estariam dispostas na coluna da esquerda da tela enquanto os campos são exibidos na parte central, facilitando a visualização de todos os campos de edição. A Figura 13 ilustra o exemplo citado.

Outra sugestão de melhoria refere-se à exibição das Metas e Etapas cadastradas. Se o usuário expandir as informações de cada registro, as informações ficam difíceis de ler devido à paleta de cores selecionada para distinção de cada linha. A Figura 14 ilustra o problema mencionado. Como sugestão de melhoria, utilizar uma paleta de cores diferente para distinção das linhas dos registros das Metas e das linhas dos registros das Etapas.

Uma das sugestões realizadas pelo participante 3 é a forma como são exibidos os campos de pesquisa dos Convênios. No protótipo os campos foram distribuídos em três abas (Geral, Específico e Avançado). Como sugestão de melhoria, o participante 3 indicou a remoção das abas Específico e Avançado e organizar os campos destas duas abas em uma nova tela denominada Pesquisa Avançada.

Outra sugestão de melhoria é em relação ao cadastro dos Convênios. No protótipo os campos foram distribuídos e organizados em abas. $\mathrm{O}$ preenchimento de alguns destes campos depende de informações previamente preenchidas em abas anteriores. Como sugestão de melhoria o testador indicou formatar o processo de cadastro do Convênio parecido com o processo de pagamento de uma loja

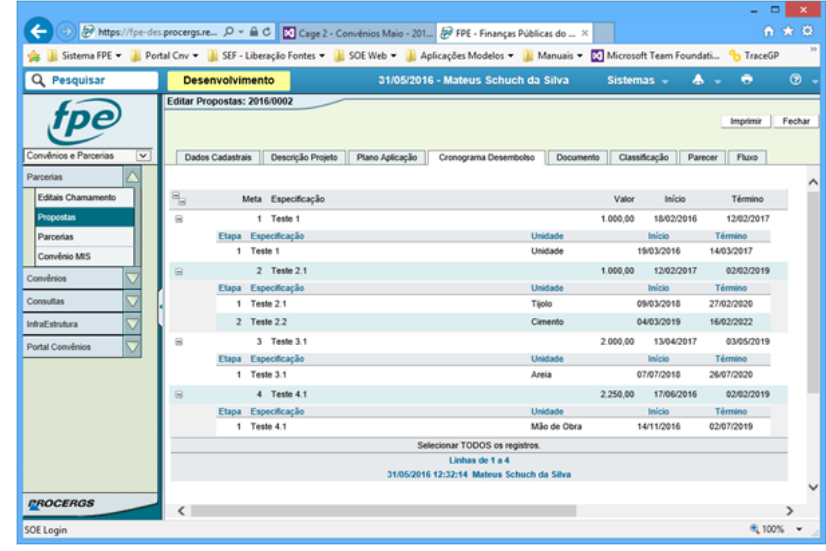

Figura 14: Tela de exibição das Metas e Etapas

virtual, onde são exibidos os campos iniciais para preenchimento e um botão denominado Avançar, exibindo os campos seguintes.

\subsubsection{Considerações finais}

O processo de análise da usabilidade do Sistema FPE demonstrou ser eficaz no objetivo de ajudar no desenvolvimento de sistema a partir da visão de usuários, aprendendo quais os aspectos detalhados da interface são bons ou ruins, e como o design pode ser melhorado. As avaliações heurísticas, através de reconhecidos princípios de usabilidade e padrões amplamente usados ou do conhecimento de todos, serviram como ponto de partida para avaliação das interfaces do sistema e para identificar os primeiros sinais de problemas de usabilidade existentes.

Nos testes de usabilidade, devido aos cuidados tomados no planejamento das sessões de testes e com o bem-estar dos usuários, deixando claro que o que estava sendo testado era o sistema, foram alcançados resultados úteis e relevantes sobre a usabilidade do sistema. Os participantes se sentiram confortáveis com a execução das rodadas de testes, sendo receptíveis e entusiasmados com a ideia de realização dos testes como parte do processo de desenvolvimento das interfaces do Sistema de Gestão FPE.

O trabalho realizado evidenciou a importância do envolvimento dos usuários no processo de avaliação das interfaces, integrante do processo de design, pois pode-se conhecer melhor aquilo que eles querem como sistema e os problemas que são experimentados. Grande parte dos erros encontrados durante a execução da avaliação heurística também foram encontrados nas rodadas de testes, sendo que os erros encontrados com o primeiro participante se repetiram com o segundo, e assim por adiante, confirmando a teoria de Nielsen (2000) de que não são necessários muitos usuários para encontrar grande parte dos erros de usabilidade existentes nos sistemas.

Quanto às sugestões de melhorias, apresentadas no formato de protótipo, foram bem aceitas pelos usuários, tendo poucos erros localizados e algumas sugestões de alteração para melhor desempenho e apresentação. Uma sugestão de alteração sugerida é a permanência das abas no formato atual na tela de cadastro de novo Convênio. A ideia exposta no protótipo de dispor as abas como accordion (sanfona) 
poderá gerar dúvidas no usuário se todos os campos da aba foram preenchidos, já que nem todos os campos de cada aba são exibidas na sua totalidade, sendo necessário rolar a barra de rolagem.

Também foi sugerido o ajuste de identação dos dados exibidos na lista da aba Metas, alinhando as informações das Etapas mais para direita logo abaixo das informações da Meta, e a alteração na paleta de cores da lista deixando mais claro o agrupamento de dados entre Metas e suas Etapas.

Há evidente constatação com a conclusão deste trabalho da importância de explorar os processos de avaliação das interfaces não somente como fase única dentro do processo de design, mas como parte integrante no ciclo de vida do projeto (Rocha and Baranauskas; 2003, p. 161). Desta forma será possível obter um sistema mais consistente, menos suscetível a erros e com uma ótima eficiência, eficácia e satisfação por parte dos usuários.

\section{Conclusão}

Hoje o uso da Tecnologia da Informação e da Comunicação (TIC) faz parte da vida dos seres humanos, seja através da navegação na web, aplicativos no celular, botões de painéis de eletrodomésticos, ou ainda, utilizando sistemas para realizar as atividades de trabalho. Por isso, antes da construção de interfaces é importante realizar um estudo da usabilidade, de forma que o projeto do design do sistema seja centrado nas pessoas e que possa satisfazer suas necessidades. A área Interação Humano-Computador auxilia neste processo de validação da usabilidade e coloca em foco o usuário, projetando "[...] sistemas interativos que favoreçam as pessoas e dos quais elas possam usufruir"(Benyon; 2011, p. 6).

A usabilidade dos sistemas está atrelada a cinco atributos: Facilidade de Aprendizagem, atributo mais importante da usabilidade, onde o sistema deve ser fácil de aprender a ponto que o usuário possa rapidamente iniciar seu trabalho neste sistema; Eficiência, a ponto que, uma vez o usuário ter aprendido sua utilização, ele possa ter um alto nível de produtividade; Facilidade de Relembrar, onde o usuário seja capaz de retornar ao sistema após um período sem uso, sem a necessidade de ter que aprender tudo de novo; Erros, onde o sistema deve ter uma baixa taxa de erros, ou seja, o usuário não pode cometer muitos erros durante o seu uso e, ocasionando o erro, ele deve conseguir retornar facilmente a utilização normal; e por fim o atributo Satisfação Subjetiva, cujo sistema deve ser agradável de ser utilizado, onde o usuário esteja subjetivamente satisfeito ao utilizá-lo, expressando o efeito do uso do sistema sobre as emoções e os sentimentos do usuário. Alguns autores, como Rogers et al. (2013), consideram essa preocupação como um critério de qualidade distinto.

A avaliação da usabilidade tem por objetivo conhecer melhor o que os usuários querem e os problemas que eles experimentam. Esta avaliação é necessária para responder questões que surgem durante o processo de design e desenvolvimento de um sistema. É comprovada que a realização da avaliação ajuda a identificar o que pode ser melhorado na interface de interação usuário-sistema, através da mostragem de erros encontrados ().

Para a avaliação de interfaces são realizadas: (1) Inspeção de Usabilidade, um conjunto de métodos baseados em se ter avaliadores inspecionando ou examinando aspectos relacionados à usabilidade de uma interface de usuário; (2) Teste de Usabilidade, que consiste basicamente na observação de uma pessoa de cada vez tentando usar algo para executar tarefas comuns a fim de que se detectem e se consertem as coisas que o confundem ou o frustram.

Diante do desafio de melhorar a interação dos usuários do Sistema de Gestão FPE, a pesquisa realizada proporcionou conhecimentos necessários para a descoberta de problemas de usabilidade e o desenvolvimento de melhorias, que possibilitaram indicar aprimoramentos para o sistema. Para isso, baseado no método de investigação que envolveu a realização de análises heurísticas em conjunto com testes de usabilidade, foram selecionados dez problemas a partir de erros encontrados nas avaliações heurísticas em conjunto com erros encontrados durante as sessões de testes.

Os problemas foram classificados com base no nível de sua importância e impacto para pleno funcionamento do sistema e sua complexidade para aprimorar e solucionar o erro descrito. Como contribuição, foi feita uma discussão entre o autor deste trabalho com o apoio de especialistas na área da Usabilidade sobre os problemas selecionados e proposto novos requisitos para a interface web do sistema, baseados em guidelines oriundas de pesquisas extensivas, revisões críticas e síntese da literatura científica, assim como também em heurísticas que objetivam descrever propriedades comuns de interfaces usáveis. Os novos requisitos propostos foram implementados em um protótipo utilizando uma dimensão horizontal, abrangendo o máximo de tarefas com pouco detalhamento na funcionalidade, e uma nova rodada de avaliação foi realizada utilizando o protótipo gerado em sessões de teste com os mesmos testadores participantes nas sessões anteriores, validando, desta forma, as características de melhoria para o Sistema de Gestão FPE.

A comprovação de que a necessidade e satisfação dos usuários foram supridas e aprimoradas através dos testes de prototipação refletem não só em uma melhor experiência de utilização do sistema pelo cidadão, como também visa aumentar a transparência e redução de custos para o Estado (Carvalho; 2015, p. 79). Também é comprovado que a adoção das metodologias e ferramentas para análise e implementação da usabilidade agrega valor e fortalece os processos interativos previstos no desenvolvimento de qualquer sistema de informática, principalmente aos sistemas de gestão utilizados pela iniciativa pública (Pires et al.; 2015).

Problemas graves poderão ocorrer aos usuários do sistema caso uma interface não apresente uma boa usabilidade. Deste modo, algumas sugestões de melhorias foram surgindo ao passo que os objetivos da pesquisa eram atingidos. Assim, os usuários terão acesso de maneira fácil e inteligente ao conteúdo do sistema caso sejam adotadas estas sugestões (Costa; 2016).

As experiências acerca das validações heurísticas e 
dos testes de usabilidade aplicadas com usuários do Sistema FPE resultaram em algumas sugestões para trabalhos futuros, que são:

- Implementar as sugestões de melhorias de usabilidade listadas na Tabela 4 da seção Execução dos teste.

- Incluir no ciclo de desenvolvimento e manutenção do Sistema FPE os processos de avaliação de usabilidade, através da avaliação heurística e testes de usabilidade.

- Manter os convites aos clientes do Sistema FPE para participarem dos processos de avaliação de usabilidade, tornando os resultados das avaliações mais fidedignas.

\section{Agradecimentos}

Agradecemos a PROCERGS - Companhia de Processamento de Dados do Estado do Rio Grande do Sul - pelo incentivo e colaboração a esta pesquisa.

\section{Referências}

Benyon, D. (2011). Interação humano-computador, $2^{\mathrm{a}}$ edn, Pearson Education do Brasil, São Paulo.

Carvalho, R. N. M. d. (2015). Usabilidade, Acessibilidade e Qualidade da Web da Administração Pública Portuguesa, Master's thesis, Instituto Universitário de Lisboa, Lisboa.

Costa, M. M. d. N. (2016). Análise da usabilidade do sistema unificado de administração pública (SUAP) do IFRN, Master's thesis, Instituto Federal de Educação, Ciência e Tecnologia do Rio Grande do Norte.

Dias, C. (2003). Usabilidade na web : criando portais mais acessiveis, 1 edn, Altabooks, Rio de Janeiro.

Justinmind (2014). Prototyping plataform for web and mobile apps - Justinmind. Disponível em http: //www. justinmind.com (Acessado 15 Abril 2016).

Krug, S. (2014). Não Me Faça Pensar - ATUALIZADO, 1 edn, Alta Books, Rio de Janeiro.

Nielsen, J. (1993). Usability Engineering, 1 edn, Morgan Kaufmann.

Nielsen, J. (2000). Why You Only Need to Test with 5 Users. Disponível em https://www.nngroup.com/articles/ why-you-only-need-to-test-with-5-users

(Acessado 21 Janeiro 2016).

Nielsen, J. (2012). Intranet Users Stuck at Low Productivity. Disponível em https://www.nngroup.com/articles/ intranet-users-stuck-low-productivity (Acessado 31 Maio 2016).

Nielsen, J. and Loranger, H. (2007). Usabilidade na web, ELSEVIER EDITORA, Rio de Janeiro.

Nielsen, J. and Mark, R. L. (1994). Usability Inspection Methods, 1 edn, John Wiley \& Sons, New York.
Pires, M. R. G. M., Gottems, L. B. D., Vasconcelos Filho, J. E., Silva, K. L. and Gamarski, R. (2015). Sistema de Informação para a Gestão do Cuidado na Rede de Atenção Domiciliar (SI GESCAD): subsídio à coordenação e à continuidade assistencial no SUS, Ciência \& Saúde Coletiva 20(6): 1805-1814.

URL: $h t t p: / / w w w . s c i e l o . b r / s c i e l o . p h p ? s c r i p t=s c i \_a r t t e x t \& p i d=S 1413-$ $81232015000601805 \& \ln g=p t \& t \ln g=p t$

PROCERGS (2016). Sistema de Finanças Públicas do Estado do Rio Grande do Sul (FPE). Disponível em https://fpe.sefaz.rede.rs (Acessado 29 Maio 2016).

Rocha, H. V. D. and Baranauskas, M. C. C. (2003). Design e Avaliação de Interfaces Humano-Computador, NIED/UNICAMP, Campinas, SP.

Rogers, Y., Sharp, H. and Preece, J. (2013). Design de Interação, 3 edn, Bookman Editora, Porto Alegre.

Sommerville, I. (2011). Engenharia de software, 9 edn, PEARSON BRASIL, São Paulo. 
Tabela 4: Problemas selecionados e sugestões de melhorias

\begin{tabular}{|c|c|c|}
\hline & Problema & Melhoria \\
\hline P1 & Abrir telas auxiliares em janelas pop-up & $\begin{array}{l}\text { Realizar a abertura das telas auxiliares em janelas } \\
\text { modais, que são janelas abertas internamente na janela } \\
\text { principal, desabilitando a página principal e colocando } \\
\text { em evidência a janela aberta. Exemplo de janela modal. }\end{array}$ \\
\hline $\mathrm{P} 2$ & $\begin{array}{l}\text { Falta de feedback do sistema em todos os tipos de } \\
\text { transação realizados pelo usuário }\end{array}$ & $\begin{array}{l}\text { Acrescentar mensagens de feedback em todo tipo de } \\
\text { transação realizada pelo usuário, como por exemplo } \\
\text { executar uma pesquisa auxiliar ou salvar um registro } \\
\text { em edição. }\end{array}$ \\
\hline P3 & Destacar o campo que está com o foco do cursor. & $\begin{array}{l}\text { Realçar o campo que está com o foco do cursor através } \\
\text { da mudança da borda do campo, deixando com a cor } \\
\text { diferente dos demais e o tamanho da borda maior. }\end{array}$ \\
\hline $\mathrm{P} 4$ & $\begin{array}{l}\text { Melhorar identificação dos campos habilitados e } \\
\text { desabilitados para preenchimento. }\end{array}$ & $\begin{array}{l}\text { Alterar para cor cinza o fundo dos campos } \\
\text { desabilitados, facilitando a identificação de quais } \\
\text { campos são editáveis e quais não são. }\end{array}$ \\
\hline P5 & $\begin{array}{l}\text { Exibir somente os campos necessários de acordo com o } \\
\text { fluxo do Convênio. }\end{array}$ & $\begin{array}{l}\text { Realizar uma análise dos principais campos necessários } \\
\text { para cada situação do fluxo do Convênio, retirando os } \\
\text { demais campos. Com o andamento do Convênio no } \\
\text { fluxo de situações, sistema exibe os campos } \\
\text { pertinentes à situação. }\end{array}$ \\
\hline P6 & $\begin{array}{l}\text { Criar uma organização lógica dos campos do } \\
\text { formulário. }\end{array}$ & $\begin{array}{l}\text { Realizar uma análise dos campos e agrupá-los de } \\
\text { acordo com a afinidade. }\end{array}$ \\
\hline P7 & $\begin{array}{l}\text { Tamanho da fonte dos textos e dos campos do } \\
\text { formulário deve seguir de acordo com a resolução da } \\
\text { janela de navegação. }\end{array}$ & $\begin{array}{l}\text { Alterar a fonte da descrição dos campos e dos campos } \\
\text { para Verdana, assim como o tamanho mínimo da fonte } \\
\text { deve ser de } 12 \text { pontos. Tamanho da fonte e dos campos } \\
\text { deve alterar de acordo com o dimensionamento da } \\
\text { janela. }\end{array}$ \\
\hline P8 & Reorganizar as abas da edição do Convênio. & $\begin{array}{l}\text { Como há uma ordem para preenchimento das abas, } \\
\text { organizar apresentação orientando a ordem correta de } \\
\text { preenchimentos destas abas. Alterar exibição das } \\
\text { informações do formato abas para o formato accordion } \\
\text { (sanfona), onde as abas são organizadas umas em cima } \\
\text { das outras, no sentido horizontal. }\end{array}$ \\
\hline P9 & $\begin{array}{l}\text { Melhorar processo de cadastramento das Metas e } \\
\text { Etapas. }\end{array}$ & $\begin{array}{l}\text { Exibir as informações das Metas e Etapas em uma } \\
\text { única página. Exemplo de exibição das informações em } \\
\text { página única. No processo de cadastro, permitir que o } \\
\text { usuário cadastre as informações da Meta e as suas } \\
\text { respectivas Etapas em uma única página, agilizando o } \\
\text { processo. }\end{array}$ \\
\hline P10 & $\begin{array}{l}\text { Melhorar a exibição dos campos na tela de edição do } \\
\text { Cronograma Previsto. }\end{array}$ & $\begin{array}{l}\text { Hoje o cadastramento do Cronograma Previsto é } \\
\text { proveniente de uma tabela na qual as colunas são os } \\
\text { meses das Metas cadastradas e as linhas são as Metas. } \\
\text { Como sugestão de melhoria, realizar a inversão do eixo } \\
\text { da tabela, ficando nas colunas as Metas e nas linhas os } \\
\text { meses. Devido à facilidade de haver vários meses para } \\
\text { exibição, facilitando a navegação da página sem } \\
\text { precisar clicar na barra de rolagem, bastando utilizar o } \\
\text { Scroll do mouse. }\end{array}$ \\
\hline
\end{tabular}

